\title{
Clinical detectable tension in the growing body: new and revisited aspects in (de-)formation of the growing spine. Can lordotic bracing technique be seen as neuromuscular tension regulation in stead of osseous correction?
}

\author{
Piet JM van Loon* and DirkJan Wever
}

Address: Department of Orthopedic Surgery, Slingeland Ziekenhuis Doetinchem, The Netherlands

* Corresponding author

\author{
from $5^{\text {th }}$ International Conference on Conservative Management of Spinal Deformities \\ Athens, Greece. 3-5 April 2008 \\ Published: 15 January 2009 \\ Scoliosis 2009, 4(Suppl I):PI doi:I0.I|86/I748-7|6|-4-SI-PI
}

This abstract is available from: http://www.scoliosisjournal.com/content/4/SI/PI

(C) 2009 van Loon and Wever; licensee BioMed Central Ltd.

\section{Background}

The unclear etiologies for scoliotic and kyphotic deformities of the spine are responsible for uncertainty in treatment options. A constant reference to what normal growth and to what the optimal construction of the entire spine should be at the end of growth is lacking.

Newly developed examination of sitting children with testing of muscular tightness is helpful. This examination highlights the different disturbances of growth that keep the spine from developing optimal configuration and thereby optimal function. Prolonged sitting of children exists only 130 years or less.

\section{Goal}

To improve the understanding of the role and characteristics of the central nervous system, especially the cord and roots in proper and improper growth of the human spine.

To clarify that preservation of lordosis and good function at the thoracolumbar junction at the end of growth can be a condition sine qua non for normal configuration and function of the spine in adult life.

\section{Methods}

Present important and consistent clinical observations in children in sitting and supine position with early and advanced adolescent deformities, both kyphotic and scoliotic by photographic studies and video fragments.
Disclosure of for the greater part unknown, experimental work on growth and deformation of the spine by Milan Roth (Brno) in German and Czech literature to propose a tension-based balancing system between central cord and the osseous and discoligamentary spine (uncoupled neuro-osseous growth).

Relate these clinical and experimental findings to common knowledge about adolescent spinal deformities and mechanical laws on tensile and compressive forces in structures.

\section{Results}

Overview of relevant clinical tests in the growing child presented with deformities shown to correlate with the proposed internal balancing problem (uncoupled neurooseeous growth) researched by Roth. Possible pathognomonic MRI signs are shown.

\section{Discussion}

By looking for scientific support for these phenomena in (bio-)mechanical literature, the work of Milan Roth was disclosed in his complete width. His embryologic studies, (neuro-) anatomical and radiological findings with their explanations, alongside interesting cadaver-, mechanicaland neuroanatomical experiments and models can bring his concept of neuro-spinal relationship in growth and misgrowth back to orthopedic daylight. Even Nicoladoni saw a century ago that a cascade of structural alterations 
takes place around the "core"-unit of the spine: the boundaries of the central canal let it stay in its place and in the shortest configuration possible in scoliosis, by suspected tensile and compressive forces. Anatomical and biomechanical consequences of keeping the spine upright in standing but more important in the sitting positions seems to fit. Children do sit for prolonged periods only in the last one or two centuries! It can be shown that the presence of these tension related clinical signs are easily leading to high compressive forces with deformation of the ventral parts in the TL-junction while sitting In literature, evidence of torsion facilitating anatomical features can be found to clarify why some spines deform in scoliosis an not in pure kyphosis.

\section{Conclusion}

By recognizing positive effects of creating lordosis at the thoracolumbar junction of the spine and by the consistent clinical findings in early deformations scientific data from Roth, the etiology of spine deformities is better understood. With the central nervous system's leading role in the growth of the spine of standing and sitting vertebrates as well as the role to steer a tension based system, the adaptations made and subsequent deformities are better understood. This tension regulating system is widely available in nature, and researched in trees. Additional research in this area for preventive measures and for therapeutic strategies in deformities seems inevitable.

\section{References}

I. Roth M: Idiopathic scoliosis caused by a short spinal cord. Acta Radiol Diagn (Stockh) 1968, 7(3):257-71.

2. Roth M: Models of vertebro-neural relations. Acta Radiol Diagn (Stockh) 1969, 9:746-53.

3. van Loon PJ, Kuhbauch BA, Thunnissen FB: Forced lordosis on the thoracolumbar junction can correct coronal plane deformity in adolescents with double major curve pattern idiopathic scoliosis. Spine 2008, 33(7):797-80I.
Publish with Bio Med Central and every scientist can read your work free of charge

"BioMed Central will be the most significant development for disseminating the results of biomedical research in our lifetime. " Sir Paul Nurse, Cancer Research UK

Your research papers will be:

- available free of charge to the entire biomedical community

- peer reviewed and published immediately upon acceptance

- cited in PubMed and archived on PubMed Central

- yours - you keep the copyright

Submit your manuscript here:

http://www.biomedcentral.com/info/publishing_adv.asp 